DOI: https://doi.org/10.21009/sarwahita.172.8

P-ISSN: 0216-7484

E-ISSN: 2597-8926

\title{
PROGRAM PSIKOEDUKASI POSITIVE PARENTING UNTUK MENINGKATKAN KUALITAS PENGASUHAN ORANGTUA DI KELURAHAN JATI ASIH, KECAMATAN JATI ASIH, KOTA BEKASI, JAWA BARAT
}

\author{
Mauna $^{1}$, Zarina Akbar ${ }^{2}$, Ernita Zakiah ${ }^{3}$ \\ Universitas Negeri Jakarta \\ ${ }^{1}$ Mauna@unj.ac.id, ${ }^{2}$ zarina_akbar@unj.ac.id, ${ }^{3}$ ernitazakiah_hrp@ymail.com
}

\begin{abstract}
Most residents in Jati Asih Urban Village, Bekasi City choose to be working parents in order to fulfill family needs. Thus, many of them leave their children under the care of the children's grandparents or caregivers. The busy schedule of these parents is one of the reasons why children rarely have time with their parents and lose direct caregiving from them. More often than not, parents also lack the understanding of the importance of quality parenting in stimulating children's development. Therefore, it is considered important to provide a psychoeducation program to the community, especially parents, to improve the quality of parenting to children through a positive parenting method. This program specifically provides psychoeducation to parents in Jati Asih Urban Village, Bekasi City. However, this program also allows participation from other parents who want to gain an understanding of positive parenting. Participants who took part in this program totaled at 216 people. Due to the COVID-19 pandemic, this program was carried out online using the Zoom application and could be attended from home. This program equipped the participants with knowledge about what positive parenting is, positive parenting techniques, the benefits of positive parenting, and tips for implementing positive parenting.
\end{abstract}

Keywords: psycoeducation, positive parenting, quality of parenting

\begin{abstract}
Abstrak
Sebagian besar warga di Kelurahan Jati Asih, Kota Bekasi bekerja untuk memenuhi kebutuhan keluarga, sehingga banyak orangtua yang menitipkan anak-anaknya untuk di asuh oleh kakek dan nenek atau pengasuh. Kesibukan orangtua, menjadi salah satu alasan anak jarang memiliki waktu bersama dengan orangtuanya, sehingga anak-anak kehilangan pengasuhan yang seharusnya di dapatkan langsung dari orangtua. Tidak jarang orangtua belum memiliki pemahaman pentingnya kualitas pengasuhan orangtua dalam menstimulasi perkembangan anak. Oleh karena, itu dinilai penting untuk memberikan program psikoedukasi ke masyarakat khususnya orangtua mengenai upaya peningkatan kualitas pengasuhan orangtua ke anak melalui metode positive parenting orangtua di Kelurahan Jati Asih, Kota Bekasi. Program ini khususnya memberikan psikoedukasi kepada orangtua yang berada di Kelurahan Jati Asih, Kota Bekasi. Namun program ini juga memberikan kesempatan kepada orangtua yang ingin mendapatkan pemahaman tentang positive parenting. Peserta yang ikut dalam kegiatan ini sebanyak 216 orang. Pelaksanaan kegiatan ini dilakukan secara daring dengan menggunakan aplikasi zoom, karena kondisi pandemic COVID-19, sehingga aktivitas tetap dilakukan di rumah. Program ini memberikan pengetahuan kepada peserta mengenai apa itu positive parenting, teknikteknik positive parenting, manfaat positive parenting, dan tips untuk melaksanakan positive parenting.
\end{abstract}

Kata Kunci: psikoedukasi, positive parenting, kualitas pengasuhan

Sarwahita : Jurnal Pengabdian Kepada Masyarakat Vol. 17 No. 2 Tahun 2020|174 


\section{PENDAHULUAN}

Kecamatan Jati Asih merupakan salah satu kecamatan yang ada di Kota Bekasi Provinsi Jawa Barat. Jumlah penduduk yang terdapat di Kecamatan Jati Asih adalah sekitar 96.806 orang atau sekitar 5,46\%. Luas wilayah $2200 \mathrm{Ha}$. Kecamatan Jati Asih terdiri dari 6 kelurahan yaitu Kelurahan Jati Asih, Jati Kramat, Jati Luhur, Jati Mekar, Jati Rasa, dan Jati Sari. Penggunaan lahan di daerah ini terdiri atas lahan terbangun dan lahan tidak terbangun. Lahan terbangun terdiri atas permukiman, industri, perdagangan dan jasa, jaringan prasarana seperti jalan, dan fasilitas sosial. Data survey di tahun 2006 sudah mencapai sekitar 70\% penggunaan lahannya didominasi oleh lahan terbangun di wilayah tersebut. Penggunaan lahan sebagian besar adalah untuk pemukiman.

Dari hasil observasi yang dilakukan karakteristik daerah tersebut yang tercermin adalah pemukiman dan pola kepadatan penduduk dalam memanfaatkan lahan terbangun. Sebagian besar warganya bekerja untuk memenuhi kebutuhan keluarga, hal ini yang menyebabkan banyak warga yang menitipkan anakanaknya untuk diasuh oleh nenek-kakek atau pengasuh anaknya, karena figur orangtuanya bekerja. Kesibukan orangtua bukan berarti menjadi berkurangnya tanggung jawab dalam mengasuh sekalipun mayoritas waktu dihabiskan di tempat kerja orangtua sebaiknya tetap memberikan pengasuhan yang tepat pada saat orangtua berada di rumah dan berinteraksi dengan anak-anaknya. Oleh karena itu dinilai penting untuk memberikan program psikoedukasi ke masyarakat khususnya orangtua mengenai upaya peningkatan kualitas pengasuhan orangtua ke anak melalui metode positive parenting.

Pengasuhan yang dilakukan nenek kakek atau pengasuh, bukan hanya sekedar pada perawatan yang sifatnya fisik misalnya dalam hal menyiapkan makanan, minuman, memandikan, menidurkan saja, pengasuhan juga dimaksudkan pada aspek psikologis, sosial, moral, dan lainnya. Kualitas pengasuhan juga berkaitan dengan cara mengasuh yang tepat sesuai dengan kebutuhan anak, dan juga stimulasi yang tepat yang diberikan kepada anak sesuai kebutuhan anak. Anak-anak memerlukan stimulasi yang tepat untuk optimalisasi pertumbuhan dan perkembangannya. Hal ini akan tercapai melalui pengasuhan yang baik karena adanya interaksi yang berkualitas dan intensif dalam keluarga tersebut.

Kualitas pengasuhan anak dalam keluarga ini sejalan dengan kerangka visi dan misi untuk kemajuan Kecamatan Jati Asih. Visi tersebut adalah "Unggul dalam Jasa Pelayanan dan Pemukiman yang Sehat bernuansa Ihsan" yang dapat ditafsirkan sebagai harapan bahwa Kecamatan Jatiasih menjadi salah satu kecamatan yang unggul dalam jasa pelayanan dan pemukiman, sehingga dapat meningkatkan taraf hidup masyarakat. Unggul dapat diartikan menunjukkan kualitas yang lebih baik, 
keinginan untuk berkembang, berproduktivitas dan efisiensi tinggi, dan memiliki daya saing tangguh. "Jasa pelayanan" meliputi pelayanan kemasyarakatan yang dilakukan pemerintah serta pelayanan jasa kegiatan ekonomi. "Pemukiman yang sehat" mengandung arti kebutuhan papan bagi masyarakat Bekasi harus sesuai dengan kaidah yang berlaku agar menciptakan kehidupan yang lebih baik; dan kata "Bernuansa ihsan" mengandung arti perisai menuju pencapaian pembangunan, aspirasi masyarakat religius dan harmonis dalam kehidupan keagamaannya.

\section{TINJAUAN LITERATUR}

Pola pengasuhan positif atau Triple $\mathrm{P}$ (positive parenting program) adalah program pengasuhan yang dikembangkan oleh (Sanders, 2008). Program ini dikembangkan untuk orangtua yang mempunyai anak dengan usia di bawah tiga tahun, pra-sekolah sampai remaja usia 16 tahun. Program ini berdasarkan prinsip pembelajaran sosial dan bertujuan untuk mengembangkan hubungan peduli yang positif antara orangtua dan anak. Program ini bertujuan untuk membantu orangtua mengembangkan strategi manajemen yang efektif untuk menangani berbagai masalah perilaku anak dan masalah perkembangan pada umumnya (Hidayanti, 2017).

Menurut Dadds \& Sanders (2006), positive parenting program (Triple-P) memiliki lima prinsip dasar:

1) Ensuring a safe and engaging environment, yaitu menyediakan lingkungan yang ramah dan aman bagi anak.

2) Creating a positive learning environment, yaitu orangtua harus merespon anak dengan konstruktif dan positif.

3) Using assertive dicipline, yaitu orangtua harus menghindari penggunaan disiplin negatif dan tidak efektif seperti menggunakan hukuman fisik.

4) Having realistic expectation, yaitu orangtua memiliki harapanharapan, kepercayaan dan asumsiasumsi tentang penyebab perilaku anak, kemudian memilih tujuan yang tepat dan realistis sesuai dengan perkembangan anak.

5) Taking care of one self as a parents, yaitu mengajarkan keterampilan pengasuhan praktis yang dapat diterapkan oleh kedua orangtua, keterampilan mengeksplorasi keadaan emosional orang tua, dan mendorong orang tua mengembangkan strategi koping untuk mengelola tekanan dan emosi negatif berkaitan dengan pengasuhan, termasuk stres, depresi, kemarahan, dan kecemasan

Sanders (2008) memiliki beberapa indikator dalam melakukan pengasuhan positif, yaitu mengenali kondisi anak, mengenali penyebab munculnya masalah perilaku anak, membuat dan menaati 
jadwal terstruktur bersama anak tanpa tekanan apapun, menyediakan lingkungan yang aman bagi anak, merespon secara positif dan membangun ketika berinteraksi dengan anak, mendorong anak belajar menyelesaikan masalahnya sendiri, mendiskusikan aturan dengan anak dan menaatinya, memberikan instruksi dan permintaan yang jelas dan tenang sesuai dengan usia perkembangan anak, berusaha tetap tenang dan berpikir positif mengenai perilaku anak. Pengasuhan positif ini berkaitan erat dengan peningkatan kualitas pengasuhan orangtua (Nooraeni, 2017).

Pola asuh adalah proses interaksi antara orangtua dan anak dalam mendukung perkembangan fisik, emosi, sosial, intelektual, dan spiritual anak sejak dalam kandungan sampai dewasa (Kemendikbud, 2016). Menurut Wood dan Zoo (dalam Sari, Saparahayuningsih \& Suprapti, 2018) pola asuh merupakan pola interaksi antara orangtua dan anak yaitu bagaimana cara, sikap, atau perilaku orangtua saat berinteraksi dengan anak. Hal ini termasuk cara penerapan aturan, mengajarkan nilai atau norma, memberikan perhatian dan kasih sayang serta menunjukkan sikap dan perilaku baik sehingga di jadikan panutan atau contoh bagi anaknya (Effendi, 2016).

\section{Pengasuhan positif adalah} pengasuhan berdasarkan kasih sayang, penghargaan, pemenuhan dan perlindungan hak anak, membangun hubungan yang hangat antara anak dan orangtua serta menstimulasi tumbuh kembang anak. Pengasuhan positif berupaya untuk memberikan lingkungan yang bersahabat dan ramah untuk anak (Kemendikbud, 2016). Pengasuhan positif dapat meningkatkan kualitas interaksi anak dengan orangtua, mengoptimalkan tumbuh kembang anak, dan mencegah perilaku menyimpang (Mubarok, 2016). Kualitas pengasuhan didefinisikan sebagai cara pengasuhan orangtua yang menyeimbangkan antara aspek tuntutan dan responsif (Efnita, 2014).

\section{METODE PELAKSANAAN}

Kegiatan ini dirancang dengan mengikuti model training dengan metode ceramah, diskusi, dan tanya jawab. Adapun tahapan-tahapan yang disusun untuk mencapai target luaran pada kegiatan pengabdian masyarakat ini adalah sebagai berikut:

1) Mempersiapkan materi tentang positive parenting, yang akan dijadikan sebagai materi di dalam poster psikoedukasi positive parenting untuk meningkatkan kualitas pengasuhan orangtua di kelurahan Jati Asih, Kecamatan Jati Asih, Kota Bekasi, Jawa Barat.

2) Mendesign poster psikoedukasi yang akan diberikan baik dalam selebaran atau bisa didapatkan juga secara online, sehingga orangtua bisa lebih mudah untuk mendapatkan poster psikoedukasi tentang positive parenting.

3) Seminar psikoedukasi tentang positive parenting untuk meningkatkan kualitas pengasuhan 
orangtua di kelurahan Jati Asih, Kecamatan Jati Asih, Kota Bekasi, Jawa Barat. Tahapan ini dimulai dengan memberikan penjelasan dengan teknik ceramah. Materi yang diberikan tentang pegertian positive parenting, teknik-teknik positive parenting, manfaat positive parenting, manfaat positive parenting, dan tips dalam menerapkan positive parenting. Saat menjelaskan materi tentang teknik-teknik positive parenting, dihadirkan salah satu bintang tamu yang memberikan contoh salah satu penerapan teknik positive parenting. Selanjutnya, diakhir penjelasan dilakukan pemutaran video tentang positive parenting.

4) Pembagian poster atau link yang bisa diakses oleh orangtua di kelurahan Jati Asih, Kecamatan Jati Asih, Kota Bekasi, Jawa Barat.

Orangtua yang menjadi peserta dalam kegiatan ini aktif selama kegiatan berlangsung, hal ini tampak dari awal sampai akhir kegiatan. Saat fasilitator menyampaikan materi, peserta aktif mendengarkan dan memberikan pertanyaan kepada fasilitator. Sebelum memulai seminar, pelaksana pengabdian masyarakat akan melakukan pre-test ke semua peserta terkait pengetahuannya akan positive parenting. Pre-test ini diberikan dengan menggunakan aplikasi survey yang ada di zoom. Pertanyaan yang dimuat di dalam pre-test tentang dengan positive parenting, hal ini dilakukan untuk melihat sejauh mana pemahaman peserta tentang positive parenting.

Post-test dilakukan setelah seminar poster psikoedukasi tentang positive parenting selesai dilakukan. Post-test ini dilakukan untuk mengevaluasi pemahaman peserta setelah diberikan poster psikoedukasi positive parenting yang dilakukan di Kelurahan Jati Asih, Kecamatan Jati Asih, Kota Bekasi, Jawa Barat.

Setelah terlaksananya kegiatan "program psikoedukasi positive parenting untuk meningkatkan kualitas pengasuhan orangtua di Kelurahan Jati Asih, Kecamatan Jati Asih, Kota Bekasi, Jawa Barat". Diharapkan para orangtua di di kelurahan jatiasih, kecamatan jatiasih, kota bekasi, jawa barat memahami tentang apa itu positive parenting, paham tentang teknik-teknik positive parenting, dan memahami cara atau tips dalam penerapan positive parenting, sehingga orangtua mampu menstimulasi perkembangan anak, sehingga anak tumbuh sehat secara fisik dan mental. Selain itu mitra program dalam hal ini orangtua di kelurahan jatiasih, orangtua di luar Kelurahan Jati Asih dan pemateri mendapatkan luaran berupa sertifikat dan poster psikoedukasi positive parenting. Program yang sudah dilaksanakan akan di publikasikan melalui media youtube.

\section{HASIL DAN PEMBAHASAN}

Kegiatan ini dilaksanakan pada hari Minggu, tanggal 28 Juni 2020, ditengah 
kondisi pandemik COVID-19 yang mengharuskan semua warga untuk melaksanakan aktivitas dari rumah, sehingga kegiatan ini dilaksanakan secara daring dengan menggunakan zoom. Peserta yang hadir dalam kegiatan ini totalnya 216 orang, yang mana perwakilan dari Kelurahan Jati Asih sebanyak 14 orang, peserta lainnya berasa dari luar daerah seperti Aceh, Jogja, Sulawesi, dan daerah lainnya.

Kegiatan dimulai dengan pengisian pre-test mengenai dasar positive parenting yang dapat diisi oleh peserta Jumlah soal yang diisi oleh peserta sebanyak 5 soal pilihan ganda dengan waktu pengerjaan selama 5 menit. Berdasarkan hasil polling pre-test, masih banyak peserta yang belum memahami apa itu positive parenting dan bagaimana teknik penerapannya. Peserta juga cukup antusias pada saat mengisi soal pre-test. Dr. Phil. Zarina Akbar, M.Psi merupakan pembicara pertama yang menyampaikan materi mengenai "Apa Itu Positive parenting?" dan "Faktor yang Memengaruhi Ketidakstabilan dalam Keluarga" dengan durasi waktu selama 20 menit.

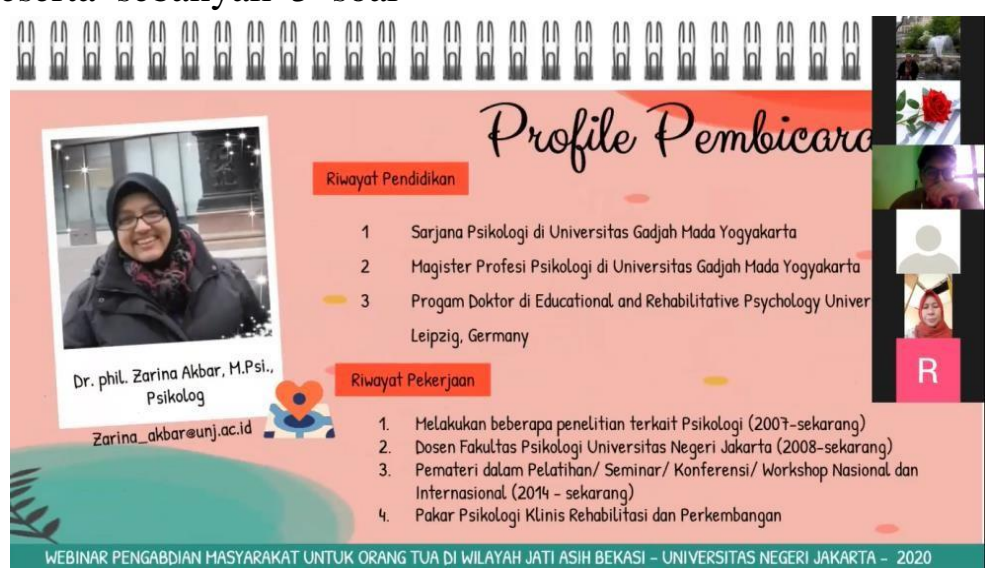

Gambar 1. Informasi Mengenai Profil Pembicara Pertama yaitu Dr. phil. Zarina Akbar, M.Psi.

Sebelum memasuki penyampaian materi yang kedua, kegiatan diselingi dengan pembagian door prize berupa buku parenting bagi peserta yang pertama kali bergabung pada acara webinar. Penyampaian materi kedua dilakukan oleh
Mauna, M.Psi yang membahas mengenai membahas materi mengenai "Teknik Umum yang Digunakan dalam Positive parenting" dan "Mengapa Positive parenting Menjadi Hal yang Penting?". 


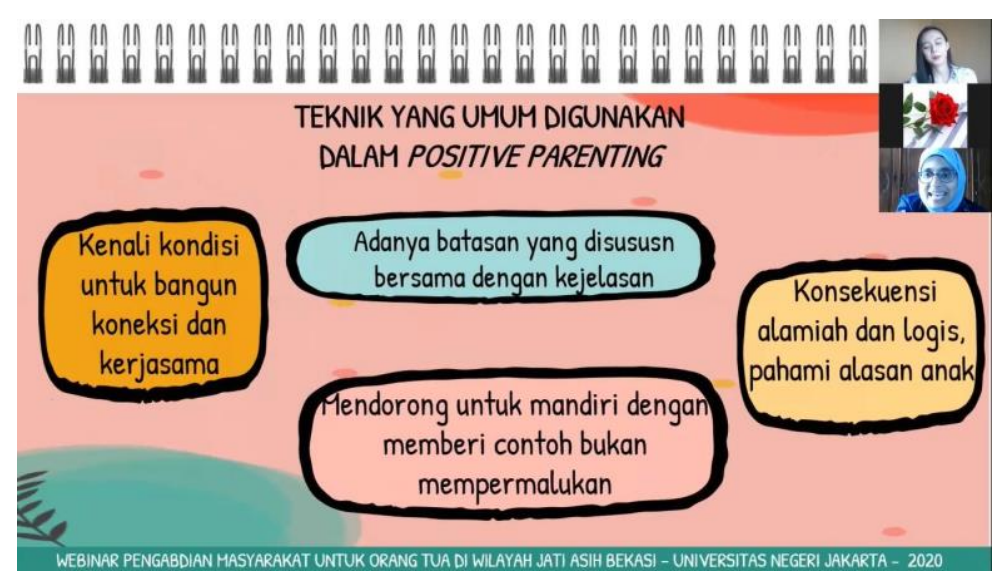

Gambar 2. Penyampaian Materi oleh Mauna, M.Psi

Seusai penyampaian materi kedua, kegiatan diselingi dengan stand up comedy. Penyampaian materi ketiga ini dilakukan oleh Ernita Zakiah, M.Psi yang membahas mengenai "Manfaat dari Positive parenting" dan "8 Tips untuk Menjalankan Positive parenting" dengan durasi waktu 20 menit.

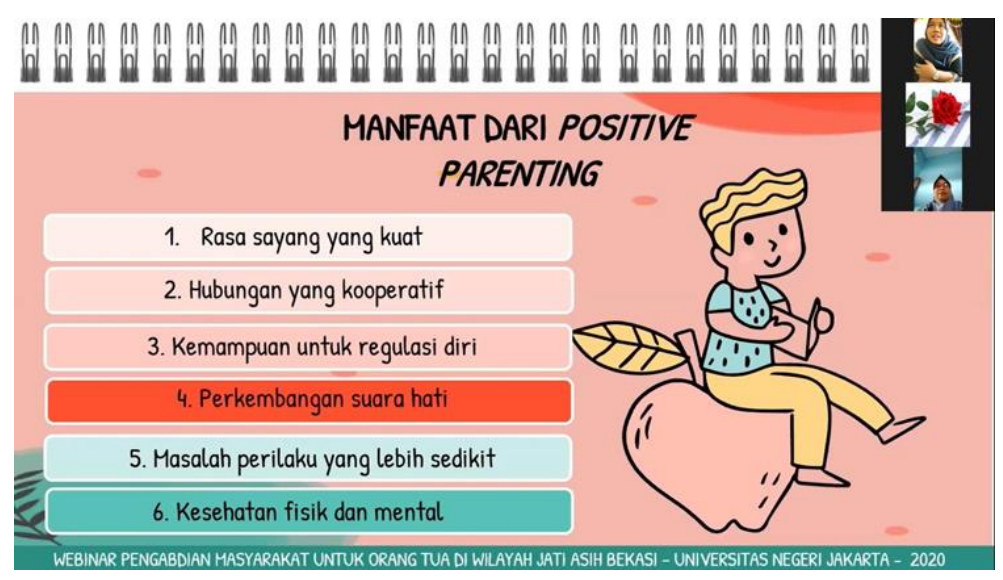

Gambar 3. Penyampaian Materi oleh Ernita Zakiah, M.Psi

Setelah seluruh materi telah tersampaikan terdapat pemutaran video mengenai positive parenting yang berdurasi sekitar 5 menit. Tujuannya adalah memberikan perspektif mengenai gambaran-gambaran yang dilakukan pada penerapan positive parenting. Pada video ini dijelaskan manfaat komunikasi pada orang tua terhadap anak, sehingga tidak menimbulkan prasangka buruk pada satusama lain. Sebelum kegiatan berakhir peserta diminta untuk mengisi post-test yang diberikan panitia di layar Zoom masing-masing peserta. Ternyata terdapat kenaikan signifikan antara hasil pre-test dan hasil post-test yang menunjukkan peningkatan pengetahuan para peserta akan positive parenting. 


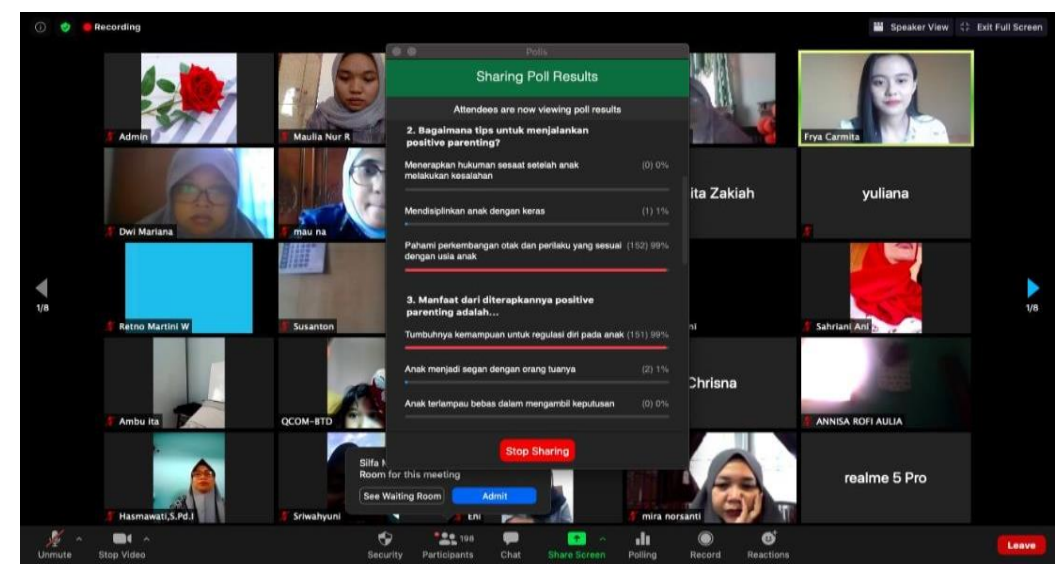

Gambar 4. Pengisian Post-test oleh Peserta

$\begin{array}{ll}\text { Selama kegiatan berlangsung } & \text { Peserta tampak antusias untuk mengikuti } \\ \text { peserta tampak antusias mengikuti } & \text { setiap rangkaian kegiatan, saat } \\ \text { kegiatan psikoedukasi yang dilakukan, hal } & \text { menghadirkan bintang tamu dan } \\ \text { ini terlihat dari antusias peserta untuk } & \text { pemutaran video tentang parenting. Hal ini } \\ \text { mengungkapkan pertanyaan yang } & \text { juga ditunjukkan oleh respon baik peserta } \\ \text { berkaitan dengan materi yang disampaikan } & \text { lewat fitur live chat sebelum kegiatan } \\ \text { ataupun berbagai/sharing pengalaman. } & \text { berakhir. }\end{array}$

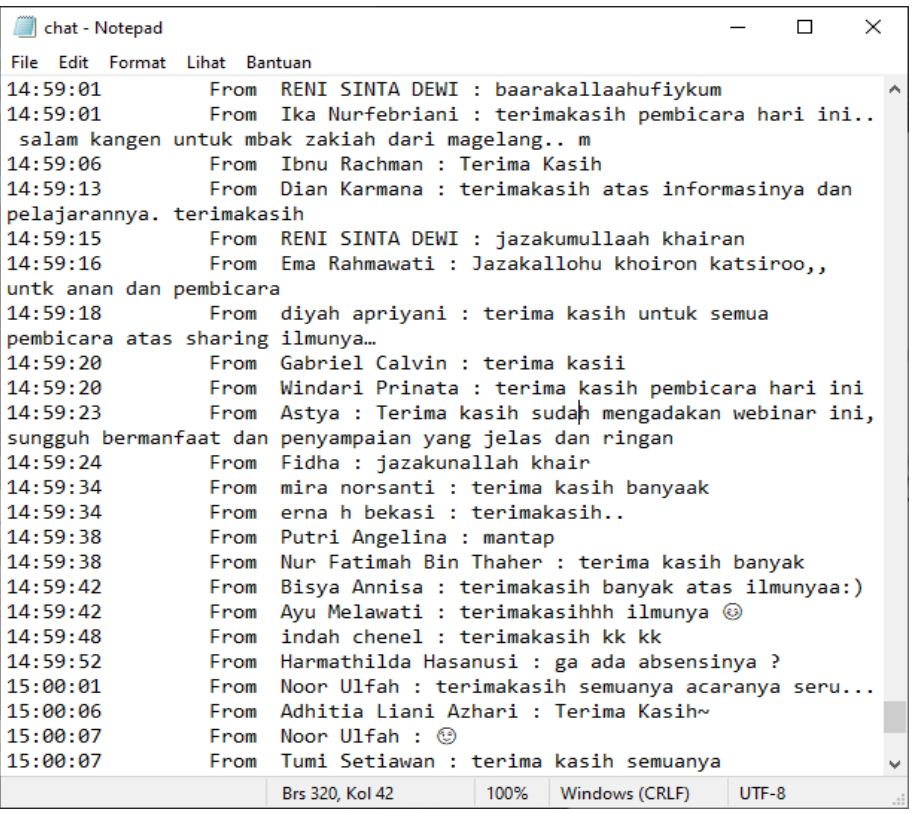

Gambar 5. Apresiasi Peserta Terhadap Kegiatan 


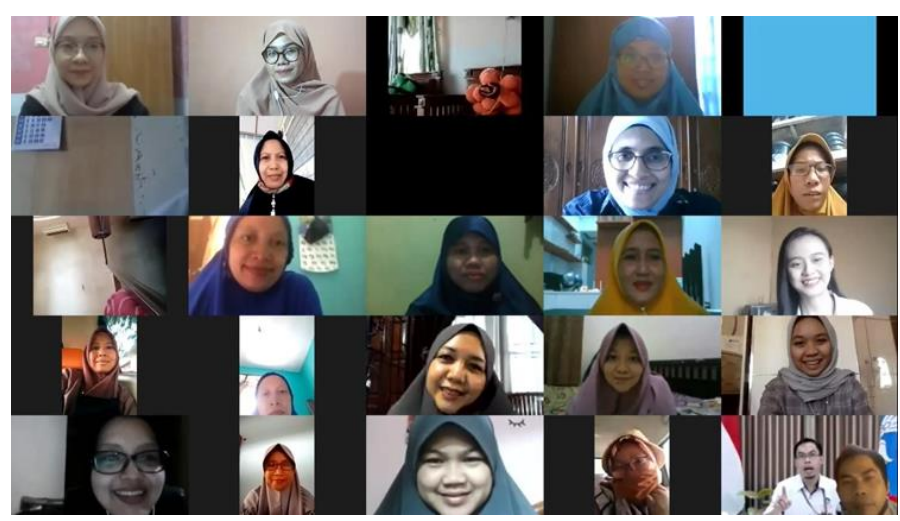

Gambar 6. Dokumentasi Kegiatan: Foto Bersama Peserta, Pembicara dan Panitia

\section{PENUTUP}

Program Pengabdian Kepada Masyarakat ini dilaksanakan kepada orangtua di Kelurahan Jati Asih, Kecamatan Jati Asih, Kota Bekasi, Jawa Barat. Program ini berjalan sesuai dengan rencana dan tanpa hambatan yang berarti. Peserta juga tampak antusias dan semangat mengikuti kegiatan yang dilaksanakan. Pelaksanaan Pengabdian Kepada Masyarakat yang dilakukan kepada orangtua di Kelurahan Jati Asih, Kecamatan Jati Asih, Kota Bekasi, Jawa Barat, dapat dinyatakan berhasil yang ditunjukkan sebagai berikut:

a) Program yang dilaksanakan sesuai dengan kebutuhan orangtua untuk meningkatkan kualitas pengasuhan melalui positive parenting

b) Peserta memberikan respon yang positif, karena merasa bahwa kegiatan yang dilakukan sesuai kebutuhan, sehingga peserta banyak yang mengusulkan agar kegiatan ini berkelanjutan

c) Hampir seluruh peserta mendapatkan pemahaman tentang positive parenting, setelah diberikan psikoedukasi

d) Hampir setiap peserta ingin memulai menerapkan positive parenting dalam pengasuhan anak-anaknya, yang sebelumnya masih sering memberikan punishment kepada anak-anak

Berdasarkan evaluasi yang dilakukan dari pelaksanaan program yang diberikan kepada orangtua di Kelurahan Jati Asih, Kecamatan Jati Asih, Kota Bekasi, Jawa Barat, dibutuhkan tambahan waktu pelaksanaan agar peserta memiliki waktu yang cukup untuk mendapatkan jawaban langsung pertanyaan yang diajukan, dan lebih banyak waktu untuk berdiskusi. Program ini tidak hanya dilakukan sekali, tetapi menjadi kegiatan yang berkelanjutan.

\section{DAFTAR PUSTAKA}

Dadds, M, C., \& Sanders, M. R. (2006). Self-Directed Triple $\mathrm{P}$ (Positive parenting Program) for Mothers With Children At-Risk of Developing Conduct Problems. Behavioural and 
Cognitive Psychotherapy, 34(3), 259275. doi:10.1017/S1352465806002797. Effendi, N. (2016). Psikologi Positif, Teori dan Terapan untuk Perubahan. Jawa Barat: Goresan Pena.

Efnita, S. (2014). Program Pengasuhan Positif untuk Meningkatkan Kualitas Pengasuhan Ibu. Thesis (Tidak Diterbitkan). Program Magister Profesi Psikologi UGM.

Hidayanti, Y. (2017). Peranan Pola Asuh Orang Tua terhadap Kemandirian Anak di Kelompok B1 Raudhatul Athfal Al Ikhlas Palu. Bungamputi, 4(2), 1-13.

Kementerian Pendidikan dan Kebudayaan. (2016). Buku Saku Pengasuhan Positif. Direktorat Pembinaan Pendidikan Keluarga, Dirjen Anak Usia Dini dan Pendidikan Masyarakat.

Mubarok, P. P. (2016). Program Pengasuhan Positif untuk Meningkatkan Keterampilan Mindful Parenting Orangtua Remaja. PSYMPATHIC: Jurnal Ilmiah Psikologi, 3(1), 35-50.
Nooraeni, R. (2017). Implementasi Program Parenting dalam Menumbuhkan Perilaku Pengasuhan Positif Orang Tua di PAUD Tulip Tarogong Kaler Garut. Jurnal Pendidikan Luar Sekolah, 13(2), 3141.

Sanders, M. R. (2008). Triple P-Positive parenting Program as a Public Health Approach to Strengthening Parenting. Journal of Family Psychology, 22(3), 506-517.

Sari, D. K., Saparahayuningsih, S., \& Suprapti, A. (2018). Pola Asuh Orang Tua Pada Anak Yang Berperilaku Agresif (Studi Deskriptif Kuantitatif Di Tk Tunas Harapan Sawah Lebar Kota Bengkulu). Jurnal Ilmiah Potensia, 3(1), 1-6.

Wijaya, Y. D. (2015). Positive parenting Program (Triple P) Sebagai Usaha untuk Menurunkan Pengasuhan Disfungsional pada Orangtua yang Mempunyai Anak Berkebutuhan Khusus (dengan Diagnosa Autis dan ADHD). Jurnal Psikologi, 13(1), 2125. 